\title{
ELECTROCHEMICAL, ESR, THEORETICAL STUDIES AND in vitro ANTI-T. cruzi ACTIVITY OF 2-ORGANOMETALLIC-5-NITRO-BENZIMIDAZOLES
}

\author{
GERMÁN BARRIGA-GONZÁLEZ ${ }^{1 *}$, CARLA OLIVARES-PETIT ${ }^{1}$, PATRICIA M. TORO ${ }^{2}$, A. HUGO KLAHN ${ }^{2}$, \\ CLAUDIO OLEA-AZAR ${ }^{3}$, JUAN D. MAYA ${ }^{4}$, YOSSELIN HUENTUPIL ${ }^{5}$ AND RODRIGO ARANCIBIA ${ }^{5 *}$
}

\author{
${ }^{1}$ Facultad de Ciencias Básicas, Universidad Metropolitana de Ciencias de la Educación, Santiago, Chile. \\ ${ }^{2}$ Instituto de Química, Pontificia Universidad Católica de Valparaíso, Casilla 4059, Valparaíso, Chile. \\ ${ }^{3}$ Facultad de Ciencias Químicas y Farmacéuticas, Universidad de Chile, Casilla 233, Santiago, Chile. \\ ${ }^{4}$ Instituto de Ciencias Biomédicas, Facultad de Medicina, Universidad de Chile, Santiago, Chile. \\ ${ }^{5}$ Facultad de Ciencias Químicas, Universidad de Concepción, Concepción, Chile.
}

\begin{abstract}
The bioorganometallic compounds 2-cyrhetrenyl-5-nitro-benzimidazole (Bzn-1) and 2-ferrocenyl-5-nitro-benzimidazole (Bzn-2) have been proposed as potential anti-Trypanosoma cruzi agents. In this regard, electrochemical, electron spin resonance and biological studies were carried out. Cyclic voltammetry experiments showed the generation of nitro anion radical derivatives and a self-protonation process was observed. Nitro anion radicals generated were characterized and analyzed using electron spin resonance spectroscopy. The compounds were tested in vitro against Trypanosoma cruzi (Dm28c strain). Biological evaluation display that 2cyrhetrenyl-5-nitro-benzimidazole (Bzn-1) was more active than its ferrocene analogue (Bzn-2) and purely organic derivate (Bzn-3), associated with the electronwithdrawing properties of the $\left(\eta^{5}-\mathrm{C}_{5} \mathrm{H}_{4}\right) \operatorname{Re}(\mathrm{CO})_{3}$ moiety. Finally, theoretical studies were carried out in order to elucidate the correlation between organometallic fragment, nitro-reduction potentials and trypanocidal activity.
\end{abstract}

Keywords: Organometallic-benzimidazoles; Cyclic voltammetry; ESR; Trypanocidal activity; computational calculations, DFT.

\section{INTRODUCTION}

American trypanosomiasis (Chagas's disease) is one of the most common endemic parasitic diseases in Latin America [1], affecting over 7 million of people according to the latest WHO's report [2]. The etiological agent of this pathology is Trypanosoma cruzi (T. cruzi), a protozoan parasite sensitive to the oxidative stress [3], because its sensitivity to the redox unbalance. Two drugs are commonly used in the treatment of this pathology: nifurtimox (NFX) and benznidazole (BNZ) (Figure 1). Both drugs exploit the parasite deficiency by generating oxidative damage [4-7] and showing a similar efficacies in the acute phase. However, these drugs produce significant side effects such as peripheral neuropathy, anorexia, vomiting and allergies, as well as considerable cardiac and renal toxicity $[8-10]$.

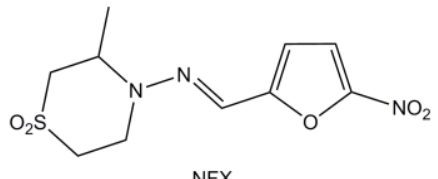

NFX

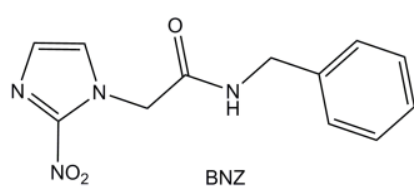

$\mathrm{BNZ}$
Figure 1. Drugs commercially available for the treatment of Chagas disease: Nifurtimox (NFX) and Benznidazole (BNZ).

While the toxic effects and the mechanisms of action of NFX and BNZ are not yet fully understood [11-13], many new antitrypanosomal agents have been developed with derivatives structurally related to these drugs [14-20]. That is, several studies propose that the bioreduction of the nitro group causes a trypanocidal effect, generating a serie of reduced metabolites of high toxicity (superoxide anion, hydrogen peroxide and hydroxyl radical) that triggers the oxidative stress into the parasite [21]. The nonselective bioreduction of both drugs may cause the toxic side effects in the mammalian host. Therefore, new effective and non-toxic antichagasic compounds need development.

Electron spin resonance (ESR) and electrochemical methods, such as cyclic voltammetry $(\mathrm{CV})$, have been used as powerful tools in the generation and identification of paramagnetic intermediates found in compounds with potential antichagasic activity [22]. Having this in mind, electrochemical parameters not only correlate with biological activity data absolutely, but they also provide important information about the potential activities of compounds [23-25].

The search of new drugs against $T$. cruzi has been focused on different strategies such as organic and inorganic compounds containing a nitro-aromatic system. These strategies have been proposed as anti-T. cruzi agents [15,26-28].
In the last years, we reported the synthesis and anti-trypanosomal evaluation of the first organometallic-organic hybrids containing 5-nitrofurane and 5nitrothiophene groups [29-34]. Biological studies against T. cruzi (epimastigotes and trypomastigotes) showed a potent trypanocidal activity of the cyrhetrenyl imines derivatives from 5-nitrofuranyl and 5-nitrothiophenyl fragments, compared with ferrocenyl or purely organic analogues. These results were correlated with the electron-withdrawing effects of cyrhetrenyl moiety [30].

Taking this into account, the auspicious reports involving organometallic groups incorporated into the nitro-aromatic rings (Figure 2) have been proposed as potential anti-Trypanosoma cruzi agents. In this regard, electrochemical, electron spin resonance and biological studies were carried out. In comparison, we have also included the organic analogue 2-phenyl-5-nitro-benzimidazole (Bzn-3). Theoretical calculations were included in order to correlate the relationship among organometallic fragment, nitro-reduction potentials and trypanocidal activity.

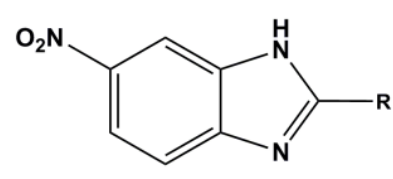

\begin{tabular}{|c|c|}
\hline Compound & R \\
\hline Bzn-1 & $\left(\eta^{5}-\mathrm{C}_{5} \mathrm{H}_{4}\right) \operatorname{Re}(\mathrm{CO})_{3}$ \\
\hline Bzn-2 & $\left(\eta^{5}-\mathrm{C}_{5} \mathrm{H}_{4}\right) \mathrm{Fe}\left(\eta^{5}-\mathrm{C}_{5} \mathrm{H}_{5}\right)$ \\
\hline Bzn-3 & $\mathrm{C}_{6} \mathrm{H}_{5}$ \\
\hline
\end{tabular}

Figure 2. Chemical structure of 2-aryl-5-nitrobenzimidazole derivatives (Bzns).

\section{EXPERIMENTAL}

\subsection{Synthesis of 2-aryl-5-nitro-benzimidazoles}

The compounds 2-cyrhetrenyl-5-nitro-benzimidazole (Bzn-1) and 2ferrocenyl-5-nitro-benzimidazole (Bzn-2) (Figure 2) were synthesized according to the methods described before [35]. The purely organic derivate 2-phenyl-5nitro-benzimidazole (Bzn-3) was obtained using equimolar amounts of 4-nitro$o$-phenylenediamine and benzaldehyde dissolved in anhydrous EtOH $(20.0 \mathrm{~mL})$. The solution was refluxed in a nitrogen atmosphere for $12 \mathrm{~h}$. The precipitate obtained was filtered and dried in vacuum. Finally, Bzn-3 was recrystallization from $\mathrm{CH}_{2} \mathrm{Cl}_{2}$ hexane (1:5) at $-10{ }^{\circ} \mathrm{C}$. Pale-brown solid. Yield: $80 \%(191.1 \mathrm{mg}$, $0.8 \mathrm{mmol}) .{ }^{1} \mathrm{H} \mathrm{NMR}\left(\mathrm{CDCl}_{3}\right): \delta 7.50\left(\mathrm{~m}, 3 \mathrm{H}, \mathrm{C}_{6} \mathrm{H}_{5}\right) ; 7.66\left(\mathrm{~s}, 1 \mathrm{H}, \mathrm{C}_{6} \mathrm{H}_{3}\right) ; 7.91(\mathrm{~s}$, $\left.1 \mathrm{H}, \mathrm{C}_{6} \mathrm{H}_{3}\right) ; 8.17\left(\mathrm{~d}, 2 \mathrm{H}, J=8.6 \mathrm{~Hz}, \mathrm{C}_{6} \mathrm{H}_{5}\right) ; 8.35\left(\mathrm{~s}, 1 \mathrm{H}, \mathrm{C}_{6} \mathrm{H}_{3}\right) ; \mathrm{NH}$ (not observed). ${ }^{13} \mathrm{C}$ NMR $\left(\mathrm{CDCl}_{3}\right): \delta 106.4\left(\mathrm{C}_{6} \mathrm{H}_{3}\right) ; 118.4\left(\mathrm{C}_{6} \mathrm{H}_{3}\right) ; 118.6\left(\mathrm{C}_{6} \mathrm{H}_{3}\right) ; 127.5\left(\mathrm{C}_{6} \mathrm{H}_{5}\right)$; $129.2\left(\mathrm{C}_{6} \mathrm{H}_{5}\right) ; 131.1\left(\mathrm{C}_{6} \mathrm{H}_{5}\right) ; 134.0\left(\mathrm{C}_{6} \mathrm{H}_{5}\right) ; 136.4\left(\mathrm{C}_{6} \mathrm{H}_{3}\right) ; 141.8\left(\mathrm{C}_{6} \mathrm{H}_{3}\right) ; 158.6$ $\left(\mathrm{C}_{6} \mathrm{H}_{3}\right)$. Mass spectrum $(\mathrm{m} / \mathrm{z}): 239\left[\mathrm{M}^{+}\right]$. Anal. (\%) Calc. for $\mathrm{C}_{13} \mathrm{H}_{9} \mathrm{~N}_{3} \mathrm{O}_{2}: \mathrm{C}, 65.27$; $\mathrm{H}, 3.79$ and N, 17.56; found: $\mathrm{C}, 65.38 ; \mathrm{H}, 3.67$ and $\mathrm{N}, 17.50$. 


\subsection{Cyclic voltammetry}

Electrochemical studies were performed at room temperature using a Metrohm 693VA instrument equipped with a 694 VA Stand convertor and 693 VA Processor with a one-compartment three-electrode system containing a hanging mercury drop electrode (HMDE) as the working electrode, a platinum wire as the auxiliary electrode and a saturated calomel electrode (SCE) as the reference electrode. The reduction potentials of the complexes were measured using DMSO solutions, which were $4 \mathrm{mM}$ in the sample and contained tetrabutylammonium perchlorate (TBAP, ca. $0.1 \mathrm{~mol} \mathrm{~L}^{-1}$ ) as the supporting electrolyte in a three-electrode cell. All solutions were purged with nitrogen, and voltammograms were recorded under a blanket of nitrogen.

\subsection{ESR spectroscopy}

ESR spectra were recorded in the X band $(9.7 \mathrm{GHz})$ using a Bruker ECS 106 spectrometer with a rectangular cavity and $50 \mathrm{kHz}$ field modulation. The hyperfine splitting constants were estimated to be accurate within $0.05 \mathrm{G}$. The anion radicals were generated by electrolytic reduction in situ under the same conditions of temperature, atmosphere and concentrations stated at the CV experiments. The ESR spectra were simulated using the program WINEPR Simfonia 1.25 version.

\subsection{Biological assays: Anti-trypanosomal activity}

T. cruzi epimastigotes (Dm28c strain) were grown at $28{ }^{\circ} \mathrm{C}$ in Diamond's monophasic medium supplemented with $4 \mathrm{mM}$ hemin and fetal calf serum, which was added to a final concentration of $5 \%(\mathrm{v} / \mathrm{v})$. The compounds were prepared in $50.0 \mathrm{mM}$ stock solutions in $100 \%$ DMSO, sonicated to enhance solubility and stored at $-20{ }^{\circ} \mathrm{C}$. Further dilutions were prepared on the day of the experiment. Benznidazole (BZN) was used as a reference drug in the experiment. The compounds were tested at a starting concentration of $100-1.00 \mu \mathrm{M}$ from a stock DMSO solution. The final DMSO concentration in the culture media never exceeded $0.2 \%(\mathrm{v} / \mathrm{v})$ and had no effect by itself on the proliferation of parasites. The control was run in the presence of $0.2 \%$ DMSO and in the absence of any drug. Compounds dissolved in DMSO were added to suspensions of $3 \times 10^{6}$ epimastigotes $/ \mathrm{mL}$ and incubated for $24 \mathrm{~h}$ at $37^{\circ} \mathrm{C}$. After this period, trypanocidal activity was measured using MTT assays as described elsewhere [36]. Briefly, MTT was added to a final concentration of $0.500 \mathrm{mg} / \mathrm{mL}$ with phenazine methosulfate $(0.220 \mathrm{mg} / \mathrm{mL})$ and incubated at $37{ }^{\circ} \mathrm{C}$ for $4 \mathrm{~h}$. The parasites were solubilized in $10 \%$ sodium dodecyl sulfate- $0.01 \mathrm{M} \mathrm{HCl}$ and incubated overnight. Formazan crystal formation was measured at $570 \mathrm{~nm}$ using an ELISA spectrophotometer (Labsystems Multiskan MS, Finlandia). A full dose-response curve was constructed for all compounds to determine the concentration inhibiting $50 \%$ of parasite growth $\left(\mathrm{IC}_{50}\right.$ value). The $\mathrm{IC}_{50}$ values were obtained using non-linear dose-response curve-fitting analysis (log of concentration vs percentage of viable cells) via Graph Pad Prism 5 software [37]. Reported values are means of at least three independent experiments. Statistical significance was determined by Student's t-test to a confidence interval of $95 \%$.

\subsection{Computational calculations}

Computational calculations were carried out to rationalize the experimental results using the Density Functional Theory (DFT) [38-41]. These calculations were performed using the Gaussian '09 software package [42]. All structural optimizations were carried out using B3LYP hybrid functional to the compounds formed by $\mathrm{C}, \mathrm{N}, \mathrm{O}$ and $\mathrm{H}$. A B3LYP/LanL2DZ level was used for those structures having Fe and Re elements [43-45]. The B3LYP hybrid functional and the basis set $6-31 \mathrm{G}++(\mathrm{d}, \mathrm{p})$ were used for both open and closed shell structures at the corresponding ground electronic states [46]. The resulting geometric parameters were compared with the available structural data. Methodologies about Natural Bond Orbitals (NBO), Fukui Functions and Dual Descriptor of Reactivity were given in the Electronic Supplementary Information (ESI $\dagger$ ).

\section{RESULTS AND DISCUSSION}

As part of our continued interest in the study on the electronic influence of the organometallic entities on bioconjugates with potential antiparasitic activity [29,30,34], we decided to study 5-nitro-benzimidazoles containing ferrocenyl (electron-donating) and cyrhetrenyl (electron-withdrawing) moieties into their structure. To do this we inspired in few reports dealing with ferrocenylbenzimidazoles as fungicidal [47,48], antitumoral $[49,50]$ and antimalarial agents [35]. In addition, we selected the benzimidazole skeleton due to the pharmacological importance of this heterocyclic ring [51-54]. Particularly, benzimidazoles possessing the nitro group at the 5-position showed interesting antiprotozoal activities [55-58].

In this regard, electrochemical and spectroscopic techniques were used as powerful tools in the generation and identification of paramagnetic intermediates found in nitro-compounds with potential antichagasic activities [58]. In addition, reports in literature have established a correlation between computational study and trypanocidal effects of nitro-derivatives $[59,60]$. In fact, Soriano-Correa and coworkers correlated the antiparasitic properties of 5-nitrofurans with quantumchemical descriptors [60].

\subsection{Cyclic voltammetry (CV)}

To establish the possible correlation between the electronic effects of the organometallic fragments presented into 5-nitro-benzimidazole ring with their $\mathrm{E}_{1 / 2}$ and trypanocidal activity, we measured the reduction potentials of nitro compounds by cyclic voltammetry (CV). Under the recommended experimental conditions $[61,62]$, the organometallic nitro-heterocyclic compounds displayed similar electrochemical behaviors (Figure $3 \mathrm{a}: \mathrm{CV}$ of 2-ferrocenyl-5-nitrobenzimidazole (Bzn-2). In fact, the voltammograms showed two reduction waves appeared, one cathodic peaks $I_{\mathrm{c}}$ (approximately $-1.1 \mathrm{~V}$ ) corresponding to nitro anion radical $\mathrm{RNO}_{2}{ }^{--}$and a new wave at higher cathodic potential peak $\left(\mathrm{II}_{\mathrm{c}} / \mathrm{II}_{\mathrm{a}}\right.$, approximately $-1.5 \mathrm{~V}$ ) corresponding to the reduction of the anion $-\mathrm{ORNO}_{2}$ specie generated through a self-protonation reactions $(\mathrm{C} 1)$. This process corresponds to an acid-base equilibrium in aprotic media, a typical behavior of self-protonation phenomenon displayed by nitro-compounds with acidic moieties in their structures [63-66]. It is probably that the higher negative potential (couple $\mathrm{II}_{\mathrm{c}} / \mathrm{II}_{\mathrm{a}}$ ) of the organometallic derivatives corresponds to a decrease capacity to accept electrons due to its negative charge:

$$
\begin{gathered}
\mathrm{HNBzNO}_{2}+\overline{\mathrm{e}} \rightarrow \mathrm{HNBzNO}_{2}^{--} \\
\mathrm{HNBzNO}_{2}^{--}+\mathrm{HNRNO}_{2} \rightarrow \mathrm{HNBzNO}_{2}^{-} \mathrm{H}+\left[\mathrm{NBzNO}_{2}\right] \\
{\left[\mathrm{NBzNO}_{2}\right]^{-}+\overline{\mathrm{e}} \rightarrow \mathrm{HNBzNO}_{2}^{-2}}
\end{gathered}
$$

In order to obtain suitable conditions for the nitro-anion radical and verify the self-protonation mechanism proposed, we worked in presence of increasing amounts of aqueous $\mathrm{NaOH}(0.1 \mathrm{~mol} / \mathrm{L})$. Thus, figure $3 \mathrm{~b}$ shows the voltammograms obtained for Bzn-2 derivative in the presence of different amounts of base. The electroreduction wave $I_{c}$ gradually disappears with the increase of $\mathrm{NaOH}$ concentration when going from 0 to $1 \mathrm{mM}$, demonstrating the proposed self-pronation mechanism[63,67-69]. a)

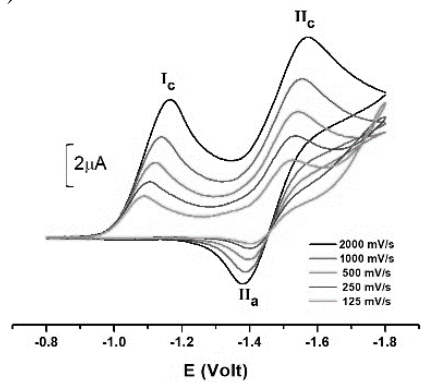

b)

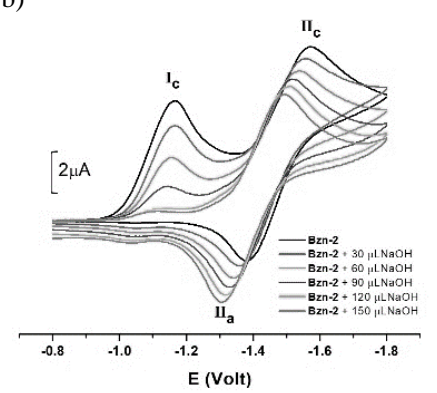

Figure 3. $\mathrm{CV}$ of Bzn-2 derivative $(1 \mathrm{mM})$ in DMSO with $0.1 \mathrm{~mol} / \mathrm{L}$ TBAP at a) different sweep rates (between 2000 and $125 \mathrm{mVs}^{-1}$ ) and b) different amounts of aqueous $\mathrm{NaOH}(0.1 \mathrm{~mol} / \mathrm{L})$, sweep rates $1000 \mathrm{mVs}^{-1}$.

On the other hand, table 1 shows the $\mathrm{E}_{1 / 2}$ values exhibited for all compounds. Bzn-1-(containing an electron-withdrawing cyrhetrenyl moiety) showed lower $\mathrm{E}_{1 / 2}$ than (Bzn-2) (containing an electron-donor ferrocenyl moiety) and phenyl (Bzn-3) (containing a phenyl moiety) analogues. In this regard, we propose that the electron-acceptor properties of cyrhetrenyl group are efficiently transferred to the benzimidazole ring, facilitating the reduction of $\mathrm{NO}_{2}$ group. Similar results have established for other organometallic-nitroheterocycle compounds that derive from (4- or 5)-nitro-furane and (4- or 5)-nitro-thiophene [30,34]. 
Table 1. Characteristic CV parameters in DMSO vs. saturated calomel electrode (sweep rate $2 \mathrm{Vs}^{-1}$ ).

\begin{tabular}{|c|c|c|c|}
\hline \multirow{2}{*}{ Compound } & \multirow{2}{*}{$\mathbf{c} \boldsymbol{E}_{1 / \mathbf{N O}_{2}}(\mathbf{V})$} \\
\cline { 3 - 4 } & & $\mathbf{H N B z N O}_{2}{ }^{--}$ & {$\left[\mathbf{N B z N O}_{2}{ }^{-2}\right]$} \\
\hline Bzn-1 & $\left(\eta^{5} \mathrm{C}_{5} \mathrm{H}_{4}\right) \operatorname{Re}(\mathrm{CO})_{3}$ & -1.03 & -1.48 \\
\hline Bzn-2 & $\left(\eta^{5}-\mathrm{C}_{5} \mathrm{H}_{4}\right) \mathrm{Fe}\left(\eta^{5}-\mathrm{C}_{5} \mathrm{H}_{5}\right)$ & -1.13 & -1.52 \\
\hline Bzn-3 & $\mathrm{C}_{6} \mathrm{H}_{5}$ & -1.11 & -1.50 \\
\hline Benznidazole & -- & -1.05 & -- \\
\hline
\end{tabular}

\subsection{Electron spin resonance}

In order to analyze the capacity of 2-organometallic-5-nitrobenzimidazoles (Bzn-1 and Bzn-2) to generate free radicals, we carried out studies by ESR spectroscopy. Bzn free radicals were prepared in situ by electrochemical reductions in DMSO, applying the potential corresponding to peak $\mathrm{II}_{\mathrm{c}}$ obtained from the $\mathrm{CV}$ experiments. Both organometallic compounds produced stable paramagnetic intermediates at that first reduction step. The interpretation of theESR by means of a simulation process confirmed the stabilities of these radical species due to the delocalization of the unpaired electron. All derivatives studied presented similar hyperfine pattern (Table 2). For example, Bzn-2 was analyzed and simulated in terms of (i) one triplet due to the nitrogen of the nitro group; (ii) three doublets due to non-equivalent hydrogen's corresponding to the benzimidazole ring (Figure 4). In all cases, the calculated hyperfine constants were in agreement with the values observed to those previously reported for compounds containing benzimidazole rings [70,71]. a)

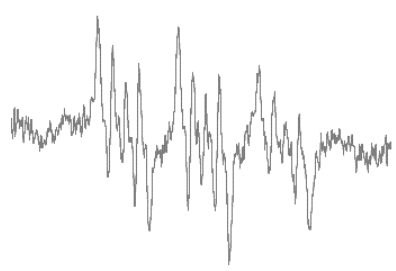

$\begin{array}{lllllllll}3410 & 3420 & 3430 & 3440 & 3450 & 3460 & 3470\end{array}$ Magnetic Field (G) b)

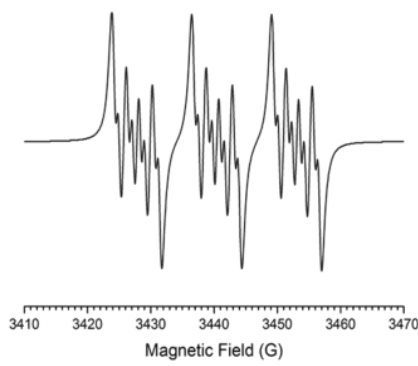

Figure 4. (a) Experimental ESR spectrum of derivative Bzn-2 nitro anion radical produced by electrochemical generation in DMSO. (b) Simulated spectrum of Bzn-2 nitro anion radical.

Table 2. Hyperfine constants (Gauss) for the anion radical of 2organometallic-5-nitrobenzimidazoles (Bzn-1 and Bzn-2).

\begin{tabular}{|c|c|c|c|c|c|}
\hline Compound & $\mathbf{R}$ & $\boldsymbol{a}_{\mathbf{N}}\left(\mathbf{N O}_{\mathbf{2}}\right)$ & $\boldsymbol{a}_{\mathbf{H}}(\mathbf{1})$ & $\boldsymbol{a}_{\mathbf{H}}(\mathbf{2})$ & $\boldsymbol{a}_{\mathbf{H}}(\mathbf{3})$ \\
\hline Bzn-1 & $\left(\eta^{5} \mathrm{C}_{5} \mathrm{H}_{4}\right) \operatorname{Re}(\mathrm{CO})_{3}$ & 12.61 & 4.09 & 2.15 & 0.87 \\
\hline Bzn-2 & $\left(\eta^{5}-\mathrm{C}_{5} \mathrm{H}_{4}\right) \mathrm{Fe}\left(\eta^{5}-\mathrm{C}_{5} \mathrm{H}_{5}\right)$ & 12.58 & 4.13 & 2.29 & 0.86 \\
\hline
\end{tabular}

\subsection{Biological assays: Antitrypanosomal activity}

To confirm the relationship among the electronic effects of the organometallic moieties on the trypanocidal activity of 5-nitrobenzimidazole skeleton, Bzns were assayed in vitro on epimastigote form of the Dm28c strain of $T$. cruzi. Table 3 shows the $\mathrm{IC}_{50}$ values that were obtained for the bioorganometallic compounds (Bzn-1 and Bzn-2). In comparison, we included the values of its organic analogue (Bzn-3) and benzimidazole drug (BNZ), which were also evaluated against the Dm28c strain. Given as a result that all tested compounds presented $\mathrm{IC}_{50}$ in the micromolar $(\mu \mathrm{M})$ range.

As seen on table 3, some general observations may be achieved. First, there was a linear correlation between the nitro-reduction $\left(E_{1 / 2}\right)$ with the anti-T. cruzi activity $\left(\mathrm{IC}_{50}\right)$. Similar results have been previously reported for related 5nitrofurane compounds with anti-chagasic activity [29,30,34]. Second, the cyrhetrenyl derivative $(\mathrm{Bzn}-1)\left(\mathrm{IC}_{50}=80 \mu \mathrm{M}\right)$ is a more potent trypanocidal agent than its ferrocenyl analogue $(\mathrm{Bzn}-2)\left(\mathrm{IC}_{50}>100 \mu \mathrm{M}\right)$. These results are related to the generation (in agreement with the electrochemical results) and a better stabilization (characterized by ESR spectroscopy) of the anion nitro radical (Bzn- $\mathrm{NO}_{2}^{-}$) in the biological target $[8,9,72-74]$.
The biological results suggested that the electronic effects of the organometallic moieties (ferrocenyl $=$ donor; cyrhetrenyl $=$ acceptor) play a relevant role in the anti- $T$. cruzi properties of 5-nitro-benzimidazoles. This hypothesis is contrasted when it was compared with trypanocidal activity registered to organic analogue $\mathrm{Bzn}-3\left(\mathrm{IC}_{50}=91 \mu \mathrm{M}\right)$, without any substitution. Similar conclusions were previously reported by our group for thiosemicarbazones, 1,3,4-thiadiazoles, chalcones and imine derivatives of 5nitroheterocycles series containing these organic and organometallic moieties [29,30,75-77]. However, all tested compounds presented IC $_{50}$ values that were higher than benznidazole drug $\left(\mathrm{IC}_{50}=44 \mu \mathrm{M}\right)$.

Table 3. In vitro anti-T. cruzi activity of 2-aryl-5-nitrobenzimidazoles.

\begin{tabular}{|c|c|c|}
\hline Compound & $\mathbf{R}$ & $\mathbf{I C}_{\mathbf{5 0}}(\boldsymbol{\mu} \mathbf{M})^{\mathbf{a}} \pm \mathbf{S E}^{\mathbf{b}}$ \\
\hline Bzn-1 & $\left(\eta^{5} \mathrm{C}_{5} \mathrm{H}_{4}\right) \operatorname{Re}(\mathrm{CO})_{3}$ & $80 \pm 0.9$ \\
\hline Bzn-2 & $\left(\eta^{5}-\mathrm{C}_{5} \mathrm{H}_{4}\right) \mathrm{Fe}\left(\eta^{5}-\mathrm{C}_{5} \mathrm{H}_{5}\right)$ & $>100$ \\
\hline Bzn-3 & $\mathrm{C}_{6} \mathrm{H}_{5}$ & $91 \pm 0.7$ \\
\hline Benznidazole & -- & $44 \pm 1.6$ \\
\hline
\end{tabular}

${ }^{a} \mathrm{IC}_{50}$ : concentration that inhibits $50 \%$ of growth. Values shown are the average of four or more experiments.

${ }^{\mathrm{b}}$ Standard error (SE).

\subsection{Computational calculations}

To rationalize the effects of the opposite electronic natures of the organometallic fragments in the 5-nitro-benzimidazole skeleton, we performed DFT calculations. The geometries of all the compounds were optimized without imposing any restrictions (Tables $\mathrm{S} 1 \dagger-\mathrm{S} 2 \dagger$ ). The analysis of the computed distances and angles showed good overall agreement versus the $\mathrm{X}$-ray diffraction data of Bzn-2. The experimental bond distances were slightly overestimated by DFT, as expected for complexes of electron-rich metals.

First, we studied the influence of the organometallic fragments in the stabilization of the radical stabilizing formed. Then, we analyzed the LUMO frontier orbitals of the Bzn-1 and Bzn-2 (Figure 5). In both cases, we observed that the cyrhetrenyl and ferrocenyl substituents do not contribute an important role in the shape of the orbital isosurface. The isosurface of the LUMO orbitals were mainly characterized by the influence of the nitro group and the benzimidazole.

a)

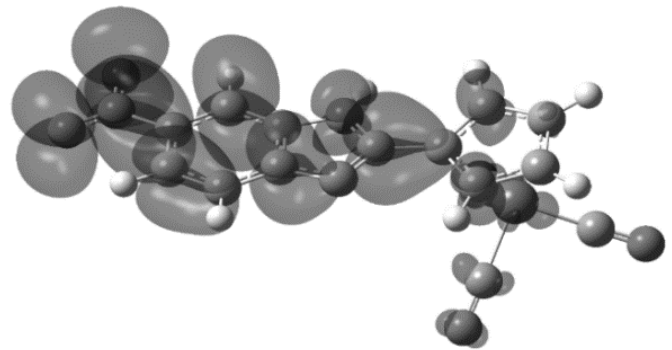

b)

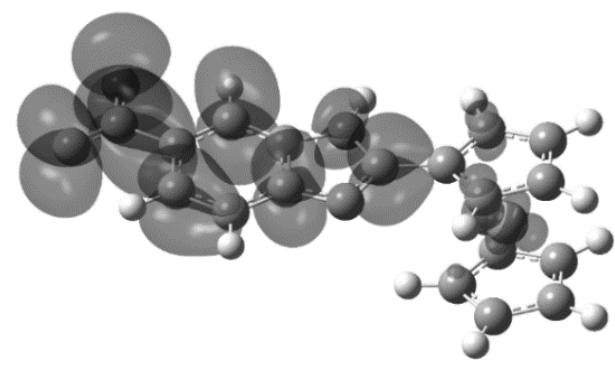

Figure 5. LUMO frontier orbitals of the a) Bzn-1 (cyrhetrenyl derivate) and b) Bzn-2 (ferrocenyl derivate).

On the other hand, it is observed that cyrhetrenyl moiety contributes significantly to the shape of the isosurface of the orbital, when we compared the SOMO orbitals for Bzn-1 and Bzn-2 (Figure 6a). However, there is a minor contribution to the SOMO orbital isosurface (Figure 6b) when changing the substituent by ferrocene. These results agree with the electrochemical and ESR characterization for these compounds (section 3.1 and 3.2) 
a)

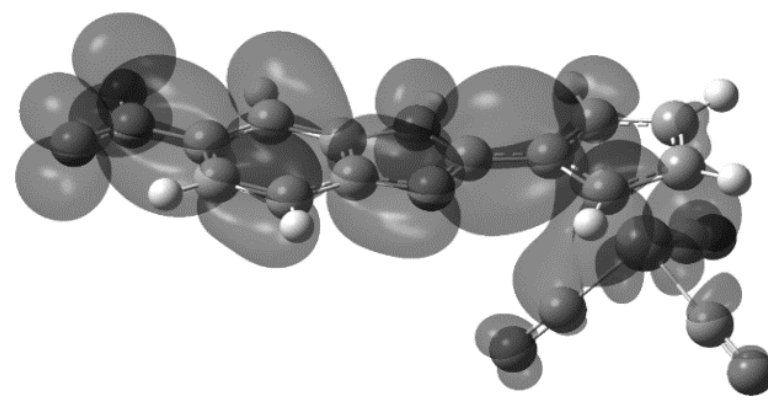

b)

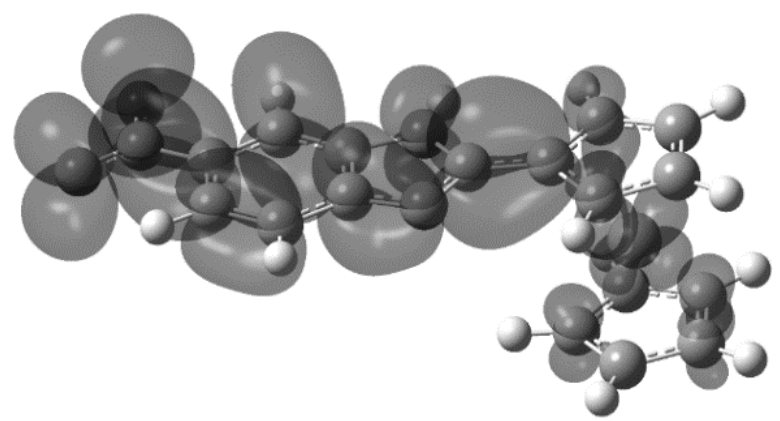

Figure 6. SOMO frontier orbitals of the a) Bzn-1 (cyrhetrenyl derivate) and b) Bzn-2 (ferrocenyl derivate).

It is important to mention that the analysis of spin densities reveals two important processes in the stabilization of the system. In the case of Bzn-1 (with substituent group cyrhetrene), there is a predominance of positive spin density (blue) which indicates that the radical is stabilized mainly by high electron delocalization (Figure 7a). In contrast, Bzn-2 (containing a ferrocenyl moiety) an increased negative spin density (green) was observed, which indicates that there are two processes: i) one dominated by spin delocalization (positive electron density) and; ii) another dominated by spin polarization (negative electron density) (Figure 7b) [78]. This leads us to conclude that a stabilization of the system is affected by such phenomena, and therefore stabilization in the presence of ferrocene group is lower compared with the cyrhetrene group. This phenomenon may be correlated with the electron-withdrawing property of the cyrhetrenyl moiety present in Bzn-1, compared to the electron-donating effect of the ferrocenyl fragment present in the analogue Bzn-2. Similar conclusions were previously reported by our group for hydrazones [79] and sulfonamides series [80] containing these organometallic moieties.

a)

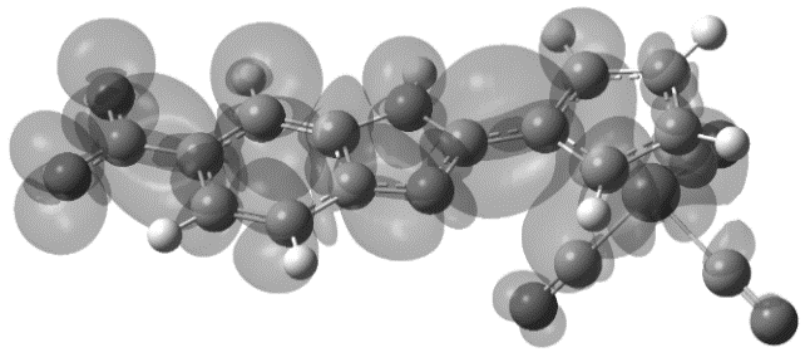

b)

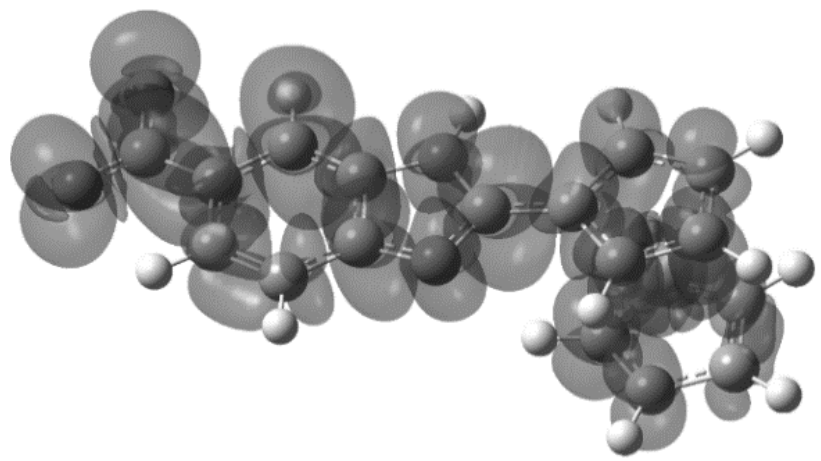

Figure 7. Spin density isosurface for the nitro radical anion for a) Bzn-1 and b) Bzn-2.
Due to Fukui function, which is an important reactivity indicator in the framework DFT theory [60], we analyzed the condensed Fukui functions for Bzn-1 and Bzn-2 to explore which atoms are potential reactive sites for electrophilic, nucleophilic or radical attacks, respectively. Tables $\mathrm{S} 3 \dagger-\mathrm{S} 4 \dagger$ displayed the condensed Fukui functions values for all atoms present in Bzn-1 and Bzn-2. In these Tables, we observed that Fukui function ( $f^{-}$for $\mathrm{C} 1$; C3; C5; $\mathrm{N} 2$ and $\mathrm{N} 3$ are sites that may suffer possible electrophilic attacks, while Fukui function $\left(f^{+}\right)$for $\mathrm{C} 2 ; \mathrm{C} 7$; $\mathrm{N} 1$ and $\mathrm{O} 2$ atoms may suffer a possible nucleophilic attack and Fukui function $\left(f^{0}\right)$ suggests for $\mathrm{N} 1$ and $\mathrm{O} 1$ atoms possible radical attacks. These results show, that the Fukui function for $\left(f^{+}\right)$and $\left(f^{0}\right)$ are located on the nitro groups; that is, the Fukui functions $\left(f^{+}\right.$and $\left.f^{0}\right)$ are similar in both molecules, which illustrate that the atoms of this group may accept electronic charge. This behavior might relate with the electron-attractor effect of the nitro group. However, it was observed a different behavior when we compared the condensed Fukui functions values $\left(f^{-}, f^{+}\right.$and $\left.f^{0}\right)$ for metal center atoms present in Bzn-1 (Re1) and Bzn-2 (Fe1). This phenomenon was correlated with the opposite electronic effect of the organometallic moieties. These results confirmed our previous observations concerning the relationship among the electronic nature of the substituent, the ability of the nitro group to be reduced and their trypanocidal properties in these types of compounds.

\section{CONCLUSION}

The 2-organometallic-5-nitro-benzimidazoles (Bzn-1 and Bzn-2) were studied by cyclic voltammetry (CV) and ESR spectroscopy. The Bzns presented a one electron reversible transfer corresponding to the generation of the nitro anion radical. The reduction mechanism depends on the acidic moieties in their structures. A self-protonation process involving the protonation of the nitro group was observed. The electrochemistry of these derivatives in presence of $\mathrm{NaOH}$ by $\mathrm{CV}$ allows to confirm the presence of acidic protons in the chemical structure of Bzns and the proposed reduction mechanism. Stable free radicals were generated using electrochemical reductions at potentials corresponding to the first wave and characterized by ESR spectroscopy. All compounds studied presented similar spectrum, due to its structural similarity. The Bzns were screened in vitro against $T$. cruzi (Dm28c strain) and moderate activities in the micromolar range $(80-100 \mu \mathrm{M})$ were observed. However, 2-cyrhetrenyl-5-nitro-benzimidazole (Bzn-1) was more active than its ferrocene analogue (Bzn-2) and purely organic derivate (Bzn-3), associated with the electron-withdrawing properties of the $\left(\eta^{5}\right.$ $\left.\mathrm{C}_{5} \mathrm{H}_{4}\right) \operatorname{Re}(\mathrm{CO})_{3}$ moiety. Finally, DFT studies were carried out in order to establish any correlation between organometallic fragment, nitro-reduction potentials and trypanocidal activity. The organometallic fragment present in the molecule helps further delocalization of unpaired electron in the radical formed. Moreover, we found that the organometallic fragments have different behaviors, which affect the properties of the studied compounds. It was observed that the organometallic fragment cyrhetrene in Bzn-1 improves the stabilization of the radical species formed unlike ferrocene fragment present in Bzn-2. Therefore, the electronic effects should be considered an influencing factor in designing new molecules with potential anti-trypanosomal activity. The correlations established are qualitative. A higher number of molecules would allow us to obtain more significant correlations.

\section{ACKNOWLEDGMENTS}

R.A. and A.H.K acknowledge FONDECYT-Chile (Project 1190327 and 1110669). R.A and Y.H. acknowledge VRID-UdeC (grant 216.021.034-1.0) for the funding of this study.

Germán Barriga González thanks to Patricio Canales Volpone from Unidad Segundo Idioma at UMCE for correcting the manuscript.

\section{REFERENCES}

1. C J Schofield, J Jannin, and R Salvatella Trends Parasitol. 22583 (2006).

2. Chagas disease, https://www.who.int/news-room/fact-sheets/detail/chagasdisease-(american-trypanosomiasis).

3. J A Urbina and R Docampo Trends Parasitol. 19495 (2003).

4. R Docampo Chem. Biol. Interact. 731 (1990).

5. R Docampo and A O M Stoppani Arch. Biochem. Biophys. 197317 (1979).

6. J D Maya, Y Repetto, M Agosín, J M Ojeda, R Tellez, C Gaule, and A Morello Mol. Biochem. Parasitol. 86101 (1997).

7. C M Sreider, L Grinblat, and A O M Stoppani Biochem. Pharmacol. 401849 (1990).

8. W Apt Drug Des. Devel. Ther. 4243 (2010). 
9. R Viotti, C Vigliano, B Lococo, M G Alvarez, M Petti, G Bertocchi, and A Armenti Expert Rev. Anti Infect. Ther. 7157 (2009).

10. M M de Mecca, S L Fanelli, L C Bartel, C R de Castro, E G Díaz, and J A Castro Life Sci. 81144 (2007)

11. S N J Moreno, R Docampo, R P Mason, W Leon, and A O M Stoppani Arch. Biochem. Biophys. 218585 (1982).

12. R Docampo, S N J Moreno, A O M Stoppani, W Leon, F S Cruz, F Villalta, and R F A Muniz Biochem. Pharmacol. 301947 (1981).

13. R Docampo and S N Moreno Rev. Infect. Dis. 6223 (1984).

14. V Duschak and A Couto Recent Patents Anti-Infect. Drug Disc. 219 (2008).

15. H Cerecetto and M Gonzalez Mini-Rev. Med. Chem. 81355 (2008).

16. M N C Soeiro and S L De Castro Expert Opin. Ther. Targets 13105 (2009).

17. F Sanchez-Sancho, N Campillo, and J Paez Curr. Med. Chem. 17423 (2010).

18. R S Keri, A Hiremathad, S Budagumpi, and B M Nagaraja Chem. Biol. Drug Des. 8619 (2015).

19. O O Ajani, D V Aderohunmu, C O Ikpo, A E Adedapo, and I O Olanrewaju Arch. Pharm. (Weinheim) 349475 (2016).

20. L V Snegur, M V Lyapunova, D D Verina, V V Kachala, A A Korlyukov, M M Ilyin, V A Davankov, L A Ostrovskaya, N V Bluchterova, M M Fomina, V S Malkov, K V Nevskaya, A G Pershina, and A A Simenel J. Organomet. Chem. 87110 (2018).

21. J R Coura Mem. Inst. Oswaldo Cruz 97441 (2002).

22. C Olea-Azar, C Rigol, F Mendizabal, and R Briones Mini-Rev. Med. Chem. 6211 (2006).

23. F C de Abreu, P A de L Ferraz, and M O F Goulart J. Braz. Chem. Soc. 13 19 (2002).

24. C Olea-Azar, A M Atria, R D Maio, G Seoane, and H Cerecetto Spectrosc. Lett. 31849 (1998).

25. C Olea-Azar, C Rigol, F Mendizabal, A Morello, J D Maya, C Moncada, E Cabrera, R Di Maio, M González, and H Cerecetto Free Radic. Res. 37993 (2003).

26. R Sánchez-Delgado and A Anzellotti Mini-Rev. Med. Chem. 423 (2003).

27. D Gambino and L Otero Inorganica Chim. Acta 47258 (2018).

28. A Singh, I Lumb, V Mehra, and V Kumar 482840 (2019).

29. R Arancibia, A H Klahn, G E Buono-Core, E Gutierrez-Puebla, A Monge, M E Medina, C Olea-Azar, J D Maya, and F Godoy J. Organomet. Chem. 696 3238 (2011)

30. R Arancibia, A H Klahn, G E Buono-Core, D Contreras, G Barriga, C OleaAzar, M Lapier, J D Maya, A Ibañez, and M T Garland J. Organomet. Chem. 74349 (2013).

31. K Karaoğlu, M Emirik, E Menteşe, A Zengin, and K Serbest 111 (2016)

32. J Gómez, A H Klahn, M Fuentealba, D Sierra, C Olea-Azar, J D Maya, and M E Medina J. Organomet. Chem. 839108 (2017).

33. P M Toro, A Acuña, M Mallea, M Lapier, M Moncada-Basualto, J Cisterna, I Brito, and H Klahn J. Organomet. Chem. 901120946 (2019).

34. P Toro, C Suazo, A Acuña, M Fuentealba, V Artigas, R Arancibia, C OleaAzar, M Moncada, S Wilkinson, and A H Klahn J. Organomet. Chem. 862 13 (2018).

35. P Toro, A H Klahn, B Pradines, F Lahoz, A Pascual, C Biot, and R Arancibia Inorg. Chem. Commun. 35126 (2013).

36. S Muelas, M Suárez, R Pérez, H Rodríguez, C Ochoa, J A Escario, and A Gómez-Barrio Mem. Inst. Oswaldo Cruz 97269 (2002).

37. n.d.

38. E J Baerends, D E Ellis, and P Ros Chem. Phys. 241 (1973).

39. E J Baerends and P Ros Int. J. Quantum Chem. 14169 (1978).

40. P M Boerrigter, G Te Velde, and J E Baerends Int. J. Quantum Chem. 3387 (1988).

41. G te Velde and E J Baerends J. Comput. Phys. 9984 (1992).

42. M J Frisch, G W Trucks, H B Schlegel, G E Scuseria, M A Robb, J R Cheeseman, Jr Montgomery J A, T Vreven, K N Kudin, J C Burant, J M Millam, S S Iyengar, J Tomasi, V Barone, B Mennucci, M Cossi, G Scalmani, N Rega, G A Petersson, et al. n.d.

43. A D Becke J. Chem. Phys. 985648 (1993).

44. C Lee, W Yang, and R G Parr Phys. Rev. B 37785 (1988).

45. P J Hay and W R Wadt J. Chem. Phys. 82270 (1985).

46. M M Francl, W J Pietro, W J Hehre, J S Binkley, M S Gordon, D J DeFrees, and J A Pople J. Chem. Phys. 773654 (1982).

47. R J Abdel-Jalil and W Voelter J. Heterocycl. Chem. 4267 (2005).

48. K H Abu-Elteen, R J Abdel-Jalil, M A Hamad, M Ghaleb, K M Khen, and W Voelter J. Med. Sci. 8673 (2008).

49. L V Snegur, A A Simenel, Y S Nekrasov, E A Morozova, Z A Starikova, S M Peregudova, Y V Kuzmenko, V N Babin, L A Ostrovskaya, N V Bluchterova, and M M Fomina J. Organomet. Chem. 6892473 (2004).

50. B Q Yang, P H Yang, and A L Zhu Chin. Chem. Lett. 14901 (2003).
51. J Rodríguez, A Gerpe, G Aguirre, U Kemmerling, O E Piro, V J Arán, J D Maya, C Olea-Azar, M González, and H Cerecetto Eur. J. Med. Chem. 44 1545 (2009).

52. Y Özkay, Y Tunali, H Karaca, and I Ișikdağ Eur. J. Med. Chem. 453293 (2010).

53. M Boiani and M Gonzalez Mini-Rev. Med. Chem. 5409 (2005).

54. J Valdez, R Cedillo, A Hernández-Campos, L Yépez, F Hernández-Luis, G Navarrete-Vázquez, A Tapia, R Cortés, M Hernández, and R Castillo Bioorg. Med. Chem. Lett. 122221 (2002).

55. H Torres-Gómez, E Hernández-Núñez, I León-Rivera, J Guerrero-Alvarez, R Cedillo-Rivera, R Moo-Puc, R Argotte-Ramos, M del Carmen RodríguezGutiérrez, M J Chan-Bacab, and G Navarrete-Vázquez Bioorg. Med. Chem. Lett. 183147 (2008).

56. E Lacey Int. J. Parasitol. 18885 (1988).

57. S Sharma, R Dubey, S Abuzar, R K Chatterjee, and J C Katiyar J. Med. Chem. 281748 (1985).

58. Z H Zhang, L Yin, and Y M Wang Catal. Commun. 81126 (2007).

59. C Echeverría, V Romero, R Arancibia, H Klahn, I Montorfano, R Armisen, V Borgna, F Simon, and R Ramirez-Tagle BioMetals 29743 (2016).

60. C Barrientos-Salcedo, B Espinoza, and C Soriano-Correa J. Mol. Struct. 1173 92 (2018).

61. C Olea-Azar, A M Atria, F Mendizabal, R Di Maio, G Seoane, and H Cerecetto Spectrosc. Lett. 3199 (1998).

62. L Thomson, A Denicola, and R Radi Arch. Biochem. Biophys. 41255 (2003).

63. C Olea-Azar, H Cerecetto, A Gerpe, M González, V J Arán, C Rigol, and L Opazo Spectrochim. Acta - Part Mol. Biomol. Spectrosc. 6336 (2006).

64. J A Bautista-Martínez, I González, and M Aguilar-Martínez Electrochimica Acta 493403 (2004).

65. J Carbajo, S Bollo, L J Núñez-Vergara, A Campero, and J A Squella $J$. Electroanal. Chem. 531187 (2002).

66. G Kokkinidis and A Kelaidopoulou J. Electroanal. Chem. 414197 (1996).

67. B Aguilera-Venegas, C Olea-Azar, E Norambuena, V J Arán, F Mendizábal, M Lapier, J D Maya, U Kemmerling, and R López-Muñoz Spectrochim. Acta - Part Mol. Biomol. Spectrosc. 781004 (2011).

68. C Maria Aravena, A Claudio Olea, H Cerecetto, M González, J D Maya, and J Rodríguez-Becerra Spectrochim. Acta - Part Mol. Biomol. Spectrosc. 79 $312(2011)$

69. J Rodríquez, C Olea-Azar, G Barriga, C Folch, A Gerpe, H Cerecetto, and M González 70557 (2008).

70. B Esat, I Fidan, S Bahceci, Y Yerli, and L Sari Magn. Reson. Chem. 47641 (2009).

71. J Valenzuela, H Pessoa-Mahana, A M Atria, M Contreras, and J Pezoa Spectrosc. Lett. 38557 (2005).

72. S R Wilkinson and J M Kelly Expert Rev. Mol. Med. 11 (2009).

73. C Bot, B S Hall, G Álvarez, R Di Maio, M González, H Cerecetto, and S R Wilkinsona Antimicrob. Agents Chemother. 571638 (2013).

74. B S Hall, C Bot, and S R Wilkinson J. Biol. Chem. 28613088 (2011).

75. R Arancibia, A H Klahn, M Lapier, J D Maya, A Ibañez, M T Garland, S Carrère-Kremer, L Kremer, and C Biot J. Organomet. Chem. 7551 (2014).

76. C Quintana, A H Klahn, V Artigas, M Fuentealba, C Biot, I Halloum, L Kremer, and R Arancibia Inorg. Chem. Commun. 5548 (2015).

77. R Arancibia, C Biot, G Delaney, P Roussel, A Pascual, B Pradines, and A H Klahn J. Organomet. Chem. 723143 (2013).

78. E Ruiz, J Cirera, and S Alvarez Coord. Chem. Rev. 2492649 (2005).

79. J Gómez, N Leiva, R Arancibia, J Oyarzo, G E Buono-Core, A H Klahn, V Artigas, M Fuentealba, R Bosque, G Aullón, C López, M Font-Bardía, and T Calvet J. Organomet. Chem. 819129 (2016).

80. C Quintana, G Silva, A H Klahn, V Artigas, M Fuentealba, C Biot, I Halloum, L Kremer, N Novoa, and R Arancibia Polyhedron 134166 (2017). 